\title{
Relation between green area duration and grain yield in some varieties of spring wheat
}

\author{
J. H. J. Spiertz, B. A. ten Hag ${ }^{1}$ and L. J. P. Kupers \\ Department of Field Crops and Grassland Husbandry, Agricultural University, \\ Wageningen, the Netherlands
}

Received: 3 July 1971

\section{Summary}

In two experiments with spring wheat the relation was studied between green area duration (D) and grain yield during the period after heading. For this, the green areas of leaf, internode and ear were determined as accurately as possible in samples.

The relation between grain yield and green area duration of the separate green organs and of combinations of these was quantified by regression and correlation calculations. These calculations heve shown that of the separate parts of the culm the $D$ values of flag leaf and peduncle were closely correlated with the grain yield.

By using the combined $D$ value of flag leaf and peduncle as a yield determining factor, 81 and $61 \%$ of the variance in the grain yield could be statistically predicted in 1967 and 1968, respectively. By including all the separate D values in a multiple correlation calculation the coefficients of determination of the variance in the grain yield could be increased to $83 \%$ in 1967 and to $74 \%$ in 1968. In 1968, next to the D values of flag leaf and peduncle, the $\mathrm{D}$ value of the ear was closely correlated to the grain yield.

The photosynthetic efficiency of the green areas was compared by the grain-leaf ratio.

\section{Introduction}

The contribution of the various green organs in the wheat plant in ear filling for many years has been a subject of study for several workers. In these studies different methods were applied, among others, shading or slipping some parts of the culm (Boonstra, 1929; Asana and Mani, 1955; Birecka, 1968; Puckridge, 1968) and measuring the rate of photosynthesis and distribution of the assimilates with ${ }^{14} \mathrm{CO}_{2}$ (Birecka et al., 1963; Stoy, 1963; Carr and Wardlaw, 1965; Lupton, 1968; Rawson and Hofstra, 1969). These studies, especially the more recent ones, show that the carbohydrates in the grain are mainly provided by the flag leaf and the peduncle (including leaf sheath) and to a less extent by the ear, and the last leaf and internode, but one. The data on the size of the contribution by each of these organs in ear filling vary widely which may be partly due to differences in experimental conditions or techniques.

In various experiments it was found that the carbohydrates for ear filling are mainly formed during the period from heading onwards (Archbold, 1942; Thorne, 1965) and

1 Present address: Research and Advisory Institute for Field Crops, Wageningen, the Netherlands. 
that from the carbohydrates formed before flowering 5 to $10 \%$ are available to the grain by re-distribution (Stoy, 1965; Wardlaw and Porter, 1967; Lupton, 1968). Therefore, the greater part of the assimilates available for ear filling is dependent on the size and the duration of the green organs in the period after flowering.

Many of these experiments were done with single plants in pots or in the field, in which the growing conditions, dependent on the treatments always deviate to a more or less extent from crop conditions. In field experiments with 'undisturbed' crops the differences in grain yield between old and new varieties have been related by Watson et al. (1963) with the size and duration of the green parts of the culm. An usual measure of the latter is the green area duration (D), the green area per unit area of land integrated over the period of grain growth. The photosynthetic efficiency of the green organs for grain filling was estimated by deviding the grain yield by the green area duration, called the grain leaf ratio $(G)$.

Welbank et al. (1966) found by calculating $G$ values, first, a good correlation between the grain yield and the green area duration, and secondly, that the standard deviation of $G$ was smaller if the green area duration only included the green area of the flag leaf and the peduncle $\left(D_{\text {Flag }}\right)$ during the period after flowering.

With reference to this work from Great Britain, two experiments were conducted with spring wheat to study which $D$ value was closed correlated to the grain yield, and in particular during which period D had to be calculated and which parts of the culm the $\mathrm{D}$ value would be composed of. By means of correlation and regression calculations the relationships between the D valves of the important green parts and the grain yields have been analysed. Should the parameter, green area duration, show a close correlation with the differences in grain yield, this might lead the breeder to make more purposeful use of genetic differences in the concerning morphological characteristics in the wheat plant and it might give the cereal grower a better idea of the effect of certain cultivation measures, as e.g. a late nitrogen application, on the production pattern of the crop.

\section{Material and methods}

The field experiments were conducted in 1967 and 1968 with spring wheat on a finetextured (about $35 \%$ clay) soil on subrecent Rhine sediments. To vary the crop structure the following treatments were applied:

1967:

- 2 varieties: 'Opal' and 'Orca'

- 3 sowing dates: 17 March, 12 April and 5 May

- 3 seed rates: $160 \mathrm{~kg}, 180 \mathrm{~kg}$ and $200 \mathrm{~kg}$ per ha

Nitrogen fertilizing was the same for all the treatments, viz $30 \mathrm{~kg} \mathrm{~N} / \mathrm{ha}$ at sowing, $20 \mathrm{~kg} \mathrm{~N} / \mathrm{ha}$ in the $\mathrm{F}_{6}$ stage and $20 \mathrm{~kg} \mathrm{~N} / \mathrm{ha}$ in the $\mathrm{F}_{10.1}$ stage (according to the Feekes scale);

1968:

- 3 varieties: 'Opal', 'Gaby' and 'Orca'

- 2 sowing dates: 4 March and 16 April

-2 CCC levels: without $\mathrm{CCC}$ and $21 \mathrm{CCC}$ per ha, applied in the $\mathrm{F}_{6}$ stage

- $2 \mathrm{~N}$ levels: $75 \mathrm{~kg} \mathrm{~N} / \mathrm{ha}$ and $75 \mathrm{~kg}+25 \mathrm{~kg} \mathrm{~N} / \mathrm{ha}$ at the beginning of flowering. 
The former experiment had a split plot design and the second a block design; both experiments were set out in four replicates. The total number of plots in 1967 and 1968 was 72 and 96 , respectively.

It has to be pointed out that the different 'crops' obtained in such an experimental design do not grow under equal conditions with respect to light intensity, temperature, precipitation, etc., although the growing periods overlap for the greater part. In the two years the climatical conditions differed to such an extent that the results are discussed separately.

To determine the dry matter weights and the green area, there were five intermediate harvests from heading onwards, viz:

$\mathrm{H}_{1}$ : when $50 \%$ of the culms were heading $\left(\mathrm{F}_{10.3}\right)$

$\mathrm{H}_{2}$ : at flowering $\left(\mathrm{F}_{10.5 .2}\right)$

$\mathrm{H}_{3}$ : two weeks after flowering

$\mathrm{H}_{4}$ : four weeks after flowering

$\mathrm{H}_{5}$ : at a grain moisture content of about $35 \%$ (1967) or six weeks after flowering (1968).

At the final harvest in $19675.4 \mathrm{~m}^{2}$ was available and $3.7 \mathrm{~m}^{2}$ in 1967 . Per intermediate harvest a sample of $0.25 \mathrm{~m}^{2}$ was harvested from each plot, of which the total dry-matter weight and the number of culms were determined. In counting, the last culm of each ten was used to make a sub-sample of 10 culms. Of these culms the following green parts were measured:

a. of each leaf lamina separately, its length $(\mathrm{cm})$ and the greatest width $(\mathrm{mm})$;

b. length $(\mathrm{cm})$ and diameter $(\mathrm{mm})$ of the internodes, including the leaf sheaths;

c. the dimensions of the stem and the ear.

After this, the ten culms were separated in leaves, stems and ears for dry-matter determination of the separate parts.

The leaf area in 1967 was obtained by multiplying the product of length and width with a correction factor (Table 1). This factor was determined at each intermediate harvest, because the shape of the green leaf area is not constant during ripening. This was done by means of photographic prints which gave the actual areas.

The date of 1967 showed a good correlation between the length and the area of the flag leaf and leaf 2, a correlation coefficient of 0.94 and 0.97 , respectively $(n=288)$. Based on this, in 1968 leaf length was used as an index for the leaf area; the leaf coefficient in this case is the quotient of the photographical area and leaf length.

The green area of the internodes (including leaf sheaths) was calculated as the area of a cylinder with the formula: height $\times$ circumference. The green area of the ear was calculated in 1967 as length $\times$ width of the separate sides; in 1968 the perpendicular projections of the sides on the horizontal plane were measured photo-electrically.

Table 1. Average leaf coefficients of flag leaf, leaf 2 and leaf 3 ; calculated as the quotient of the photographical area and the product of length and width (1967 trial).

\begin{tabular}{llll}
\hline & Flag leaf & Leaf $2 *$ & Leaf $3 *$ \\
Harvest 1 & 0.80 & 0.88 & 0.93 \\
Harvest 2 & 0.86 & 0.92 & 0.94 \\
Harvest 3 & 0.92 & 0.96 & 1.01 \\
\hline
\end{tabular}

* Leaves and internodes were numbered from top to bottom. 


\section{Results}

In both years there was a significant varietal as well as sowing date effect on the grain yields and on the size of almost all the green areas. In addition there was a great deal of interaction between the varieties and the sowing dates. The chlormequat (CCC) treatment in 1968 had significant effects on the grain yield and the green areas of some organs; this did not apply to the factor seed rate (1967) and the late top dressing of nitrogen in 1968.

\section{Green area}

The green areas of the organs are not constant during the post-floral period: the green leaf area decreases more rapidly as the leaves on the culm are older, whereas the green area of the top internodes and ear continues to increase until 14 days after flowering, when they decrease rapidly (Table 2).

The size of the green area of the various assimilating parts of the plants has also been calculated as green area index $=I$ (Fig. 1), by multiplying the green areas per culm with the number of culms per $\mathrm{m}^{2}$. The differences in green area indices (I) between the treatments were smaller than the differences in green area per culm, because a greater number of culms was accompanied by a smaller area per culm.

The size and the duration of the green parts can be expressed in one parameter, green area duration (D). This is calculated as the integral of the green area index against time. In the calculations the green area index was assumed to be linear and the green area duration can be found with the following formula:

$D=\sum_{n=2}^{e} \frac{I(n-1)+I(n)}{2} \times \frac{\text { number of day }}{7}$ (dimension: weeks)

The D values in 1967 were calculated from heading to ripening as well as from flowering to ripening; in 1968 the $\mathrm{D}$ values were also calculated for each interval between two harvests.

Of the $D_{F}$ value mentioned in Table 3 of flag leaf + peduncle + ear about $20 \%$ were realized before flowering and about $80 \%$ after; the latter percentage was divided as follows: $35 \%$ in the first 14 days after flowering, $30 \%$ in the next 14-day period and $15 \%$ in the remaining period.

In all the $D$ values there was a distinct varietal and sowing date effect, either as a major effect or as an interaction effect. The $D$ values of the late-sown treatments were

Table 2. Average green area $\left(\mathrm{cm}^{2}\right)$ of the different parts of the culm at five intermediate harvests (1967 trial).

\begin{tabular}{lrrrrr}
\hline & $\mathrm{H}_{1}$ & $\mathrm{H}_{2}$ & $\mathrm{H}_{3}$ & \multicolumn{1}{c}{$\mathrm{H}_{4}$} & $\mathrm{H}_{5}$ \\
Flag leaf & 29.1 & 29.5 & 26.7 & 15.7 & - \\
Leaf 2 & 27.8 & 26.5 & 23.5 & 3.5 & - \\
Leaf 3 & 19.9 & 17.9 & 10.3 & 0.3 & - \\
Leaf 4 & 7.7 & 6.1 & - & - & - \\
Leaf total & 85.4 & 80.3 & 61.7 & 19.5 & - \\
Peduncle & 13.7 & 28.4 & 30.8 & 23.0 & 1.5 \\
Internode & 24.8 & 24.8 & 25.1 & 20.8 & 1.8 \\
Ear & 20.1 & 25.7 & 33.7 & 27.8 & $?$ \\
\hline
\end{tabular}


A.l. of the leaves
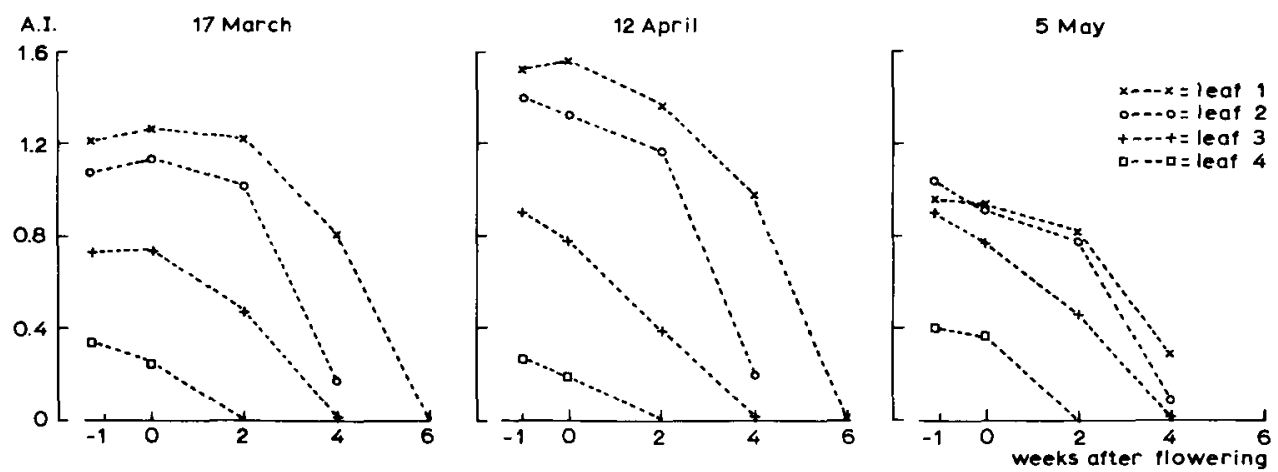

A I of the top internodes and of the ear
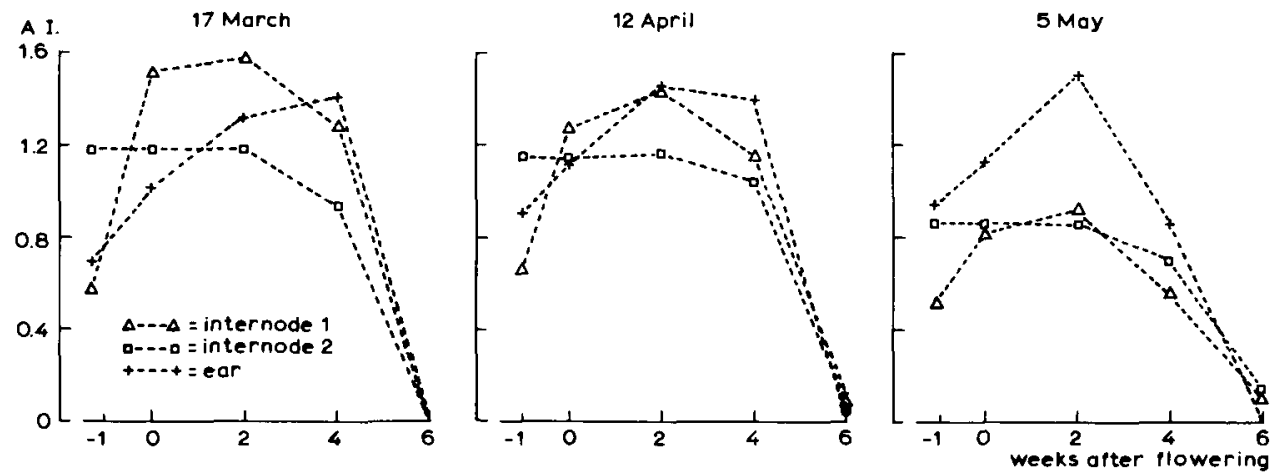

Fig. 1. Trend in the green area index (A.I.) of the separate stem parts from heading onwards with three different sowing dates.

distinctly lower than those of the early sown. This decrease was mainly due to a lower number of culms, as the result of less tillering, the sooner ripening of the late-sown treatments also affecting the $D$ values. Of the remaining treatments chlormequat (CCC) gave a significant $(\alpha<0.001)$ decrease in the $D_{F}$ value; for untreated and treated plots 19.2 and 16.5 weeks, respectively. This difference was caused by the decline in green area by chlormequat, especially of the peduncle. These data show that due to varietal characters and cultivation methods, the 'crops' differ in duration and size of the green area.

\section{Grain yield}

The grain yields were very much affected by the sowing date; especially the late-sown treatments had a much lower yield, e.g. in 'Orca' (Fig. 2). As is shown in Table 4 the sowing date effect was not identical in the two years on equal sowing dates; this was due to the differing climatical conditions.

The grain yield is composed of the following components: number of ears $/ \mathrm{m}^{2}$, number of grains/ear and the 1000-grain weight. In 1967 the 1000-grain weight was the main determinant of the grain yield $(r=0.85)$. In addition the number of ears per $\mathrm{m}^{2}$ was important $(\mathrm{r}=0.59)$, whereas the number of grains per ear did not show a 
Table 3. Green area duration (weeks) in the period from heading to ripening.

\begin{tabular}{|c|c|c|c|c|c|c|c|c|c|c|c|}
\hline \multirow{2}{*}{$\begin{array}{l}1967 \text { trial } \\
\text { Variety (V) } \rightarrow \\
\text { Sowing date }(\mathrm{S}) \rightarrow\end{array}$} & \multicolumn{3}{|l|}{ 'Opal' } & \multicolumn{3}{|l|}{ 'Orca' } & \multirow[b]{2}{*}{ mean } & \multirow[b]{2}{*}{$\sigma$} & \multirow[b]{2}{*}{$V^{\prime}$} & \multirow[b]{2}{*}{$S^{\prime}$} & \multirow[b]{2}{*}{$V S^{\imath}$} \\
\hline & $17 / 3$ & $12 / 4$ & $5 / 5$ & $17 / 3$ & $12 / 4$ & $5 / 5$ & & & & & \\
\hline Flag leaf $(F)$ & 6.4 & 7.7 & 4.2 & 7.6 & 7.4 & 4.1 & 6.2 & 0.6 & ns & $* * *$ & $* * *$ \\
\hline Leaf 2 & 5.0 & 4.9 & 3.8 & 5.0 & 5.6 & 3.6 & 4.7 & 0.5 & ns & $* * * *$ & $* *$ \\
\hline Leaf 3 & 2.2 & 1.4 & 2.1 & 3.1 & 3.2 & 3.1 & 2.5 & 0.4 & $* * *$ & $* *$ & $* * *$ \\
\hline Leaf total & 14.0 & 14.0 & 10.4 & 16.7 & 17.0 & 12.4 & 14.1 & 1.4 & $* * *$ & $* * *$ & ns \\
\hline Peduncle (P) & 8.2 & 7.6 & 4.8 & 9.6 & 7.2 & 4.4 & 7.0 & 0.8 & ns & $* * *$ & $* * * *$ \\
\hline Internode 2 & 6.4 & 6.2 & 4.6 & 7.8 & 6.8 & 5.4 & 6.2 & 0.6 & $* * *$ & $* * *$ & ns \\
\hline Ear (E) & 6.3 & 6.2 & 5.9 & 9.2 & 9.0 & 7.9 & 7.4 & 0.6 & *** & $* * *$ & $*$ \\
\hline $\mathrm{D}_{\mathrm{F}}=\mathbf{F}+\mathbf{P}+\mathrm{E}$ & 20.9 & 21.5 & 14.9 & 26.4 & 23.6 & 16.4 & 20.6 & 1.7 & $* * *$ & $* * *$ & $*$ \\
\hline $\begin{array}{l}1968 \text { trial } \\
\text { Variety (V) } \rightarrow\end{array}$ & 'Opal' & & 'Gaby & & 'Orca' & & & & & & \\
\hline Sowing date $(\mathbf{S}) \rightarrow$ & $4 / 3$ & $16 / 4$ & $4 / 3$ & $16 / 4$ & $4 / 3$ & $16 / 4$ & mean & $\sigma$ & $V^{1}$ & Si & VS 1 \\
\hline $\mathrm{D}_{\mathrm{F}}=\mathrm{F}+\mathbf{P}+\mathrm{E}$ & 23.5 & 16.5 & 20.2 & 12.9 & 21.9 & 12.2 & 17.9 & 1.6 & $* * * *$ & $* * *$ & $* * * *$ \\
\hline
\end{tabular}

Table 4. Dry matter yields (kg . ha-1) and the relevant yield components.

\begin{tabular}{|c|c|c|c|c|c|c|c|c|c|c|c|}
\hline \multirow{2}{*}{$\begin{array}{l}1967 \text { trial } \\
\text { Variety }(\mathrm{V}) \rightarrow \\
\text { Sowing date }(\mathrm{S}) \rightarrow\end{array}$} & \multicolumn{3}{|l|}{ 'Opal' } & \multicolumn{3}{|l|}{ 'Orca' } & \multirow[b]{2}{*}{ mean } & \multirow[b]{2}{*}{$\sigma$} & \multirow[b]{2}{*}{$V^{1}$} & \multirow[b]{2}{*}{ Si } & \multirow[b]{2}{*}{ VS } \\
\hline & $17 / 3$ & $12 / 4$ & $5 / 5$ & $17 / 3$ & $12 / 4$ & $5 / 5$ & & & & & \\
\hline \multicolumn{12}{|l|}{ Yield (kg . ha-1): } \\
\hline Grain & 4510 & 4527 & 3335 & 5106 & 4703 & 2943 & 4188 & 243 & $*$ & $* * * *$ & $* * *$ \\
\hline Straw & 5661 & 5747 & 4354 & 6764 & 6495 & 5324 & 5724 & 360 & $* * *$ & $* * *$ & - \\
\hline Total & 10171 & 10274 & 7689 & 11870 & 11198 & 8267 & 9912 & - & - & - & - \\
\hline \multicolumn{12}{|l|}{ Components: } \\
\hline Ears $/ \mathrm{m}^{2}$ & 404 & 412 & 328 & 502 & 474 & 420 & 423 & 20 & $* * *$ & $* * *$ & $* * ;$ \\
\hline Grains/ear & 37.8 & 42.3 & 43.2 & 33.6 & 33.2 & 34.2 & 37.4 & 3.4 & $* * *$ & $*$ & $*$ \\
\hline $\begin{array}{l}\text { 1000-grain } \\
\text { weight (g) }\end{array}$ & 38.3 & 35.9 & 33.3 & 38.7 & 38.3 & 33.4 & 36.3 & 1.0 & $* * * *$ & $\approx *$ & $* * *$ \\
\hline \multicolumn{12}{|l|}{1968 trial } \\
\hline Variety (V) $\rightarrow$ & \multicolumn{2}{|l|}{ ‘Opal’ } & \multicolumn{2}{|c|}{ 'Gaby' } & \multicolumn{2}{|l|}{ 'Orca' } & & & & & \\
\hline Sowing date $(S) \rightarrow$ & $4 / 3$ & $16 / 4$ & $4 / 3$ & $16 / 4$ & $4 / 3$ & $16 / 4$ & mean & $\sigma$ & $V^{1}$ & $\mathbf{S}^{1}$ & VSi \\
\hline \multicolumn{12}{|l|}{ Yield $\left(\mathrm{kg} . \mathrm{ha}^{-1}\right)$ : } \\
\hline Grain & 4440 & 3005 & 4155 & 2917 & 4025 & 2375 & 3486 & 420 & $* * *$ & $* *$ & ns \\
\hline Straw & 4960 & 3470 & 4390 & 3430 & 4360 & 3790 & 4068 & - & $* * *$ & $* * *$ & $* * * *$ \\
\hline Total & 9400 & 6475 & 8545 & 6347 & 8385 & 6165 & 7552 & - & $* * *$ & $* * *$ & $*$ \\
\hline \multicolumn{12}{|l|}{ Components: } \\
\hline Ears $/ m^{2}$ & 550 & 482 & 550 & 514 & 558 & 521 & 529 & 一 & $* * *$ & $* * *$ & $* *$ \\
\hline Grains/ear & \multicolumn{2}{|c|}{30.1} & \multicolumn{2}{|c|}{28.1} & \multicolumn{2}{|c|}{23.5} & 27.2 & - & $* * *$ & $一$ & - \\
\hline $\begin{array}{l}\text { 1000-grain } \\
\text { weight (g) }\end{array}$ & 33.8 & 30.6 & 32.0 & 29.3 & 35.0 & 29.2 & 31.7 & 一 & $* * *$ & $* * *$ & $* * *$ \\
\hline
\end{tabular}

ns: non-significant $(\alpha>0.05) ; * 0.05 \geqslant \alpha>0.01 ; * *: 0.01 \geqslant \alpha>0.001 ; * * *: \alpha \leqslant 0.001$. 


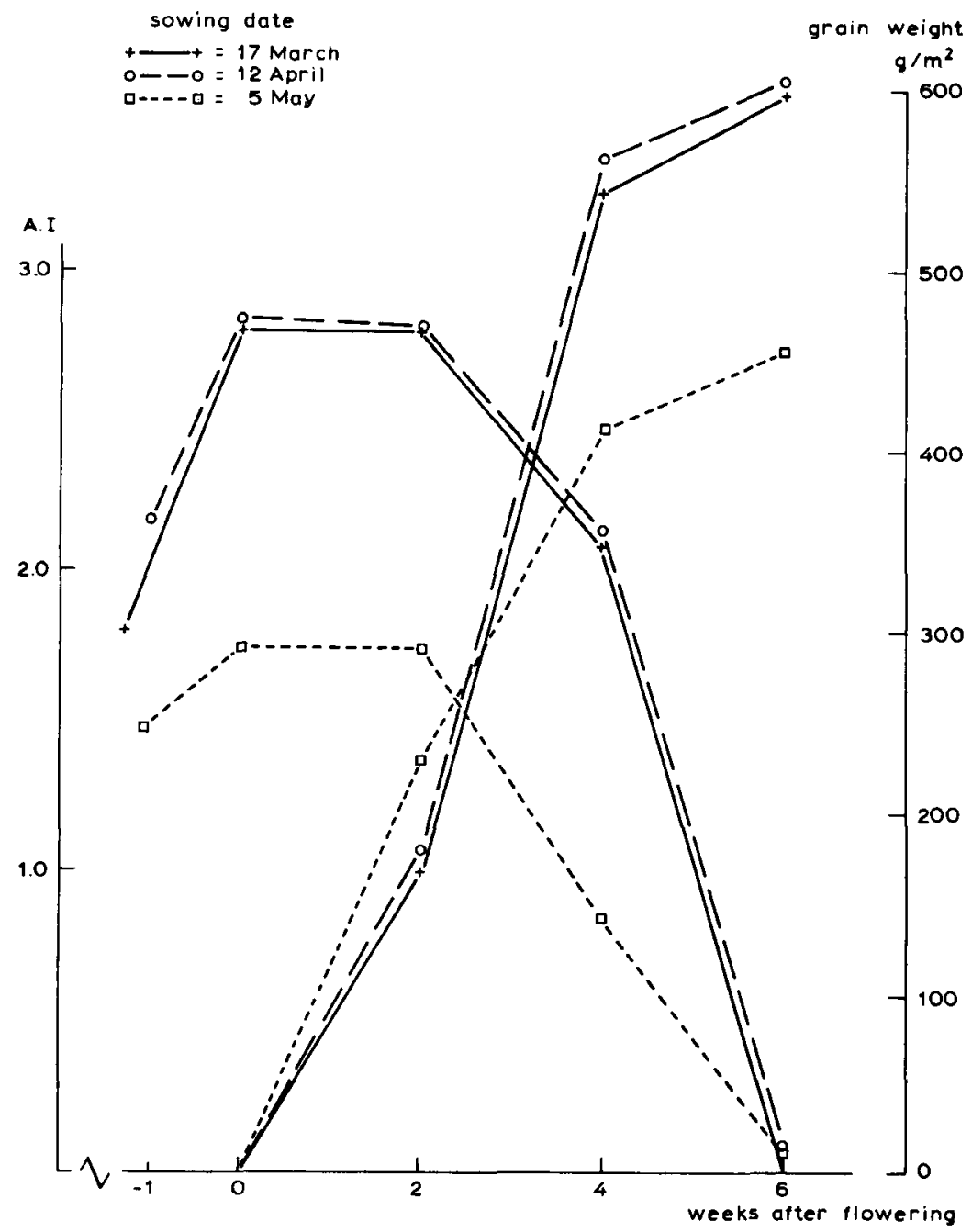

Fig. 2. Trend in green area index (A.I.) of the flag leaf + peduncle in relation to grain production with three sowing dates (1967).

significant correlation to the grain yield $(r=0.17)$.

In 1968 there were also appreciable differences in number of grains per ear between the varieties. The number of ears per $\mathrm{m}^{2}$ and the 1000 -grain weight were distinctly affected by an interaction of variety and sowing date.

Attention is called to the fact that the product of the number of ears per $\mathrm{m}^{2}$, the number of grains per ear and the 1000-grain weight is higher than the actual yield. This is due to systematic overestimation of the 1000-grain weight or the number of grains per ear and an underestimation of the actual yield due to sampling errors and threshing losses, respectively.

In the further calculations this level difference between actual and calculated yields will not be essential, because calculated and actual yields were found to be very closely correlated. 
Table 5. Estimated proportion $\left(R^{2}\right)$ of the variance in grain yield that can be attributed to its linear regression on the green area duration of the different green organs.

\begin{tabular}{|c|c|c|c|}
\hline & \multicolumn{2}{|l|}{1967 trial } & \multirow{2}{*}{$\begin{array}{l}1968 \text { trial } \\
\text { period from } \\
\text { heading on- } \\
\text { wards }(n=96)\end{array}$} \\
\hline & $\begin{array}{l}\text { period from } \\
\text { heading on- } \\
\text { wards }(\mathrm{n}=72)\end{array}$ & $\begin{array}{l}\text { period from } \\
\text { flowering on- } \\
\text { wards }(n=72)\end{array}$ & \\
\hline Flag leaf & 0.72 & 0.67 & 0.41 \\
\hline Leaf 2 & 0.53 & 0.45 & 0.38 \\
\hline Leaf 3 & 0 & 0 & 0.05 \\
\hline Leaf total & 0.47 & 0.36 & - \\
\hline Peduncle & 0.79 & 0.73 & 0.57 \\
\hline Internode 2 & 0.56 & 0.13 & 0.27 \\
\hline Ear & 0.13 & 0.16 & 0.52 \\
\hline Flag leaf + peduncle & 0.81 & 0.79 & 0.61 \\
\hline Flag leaf + leaf 2 & 0.70 & 0.63 & 0.44 \\
\hline Peduncle + internode 2 & 0.75 & 0.60 & - \\
\hline Flag leaf + peduncle + ear & 0.68 & 0.62 & 0.63 \\
\hline Flag leaf + leaf $2+$ peduncle + internode $2+$ ear & 0.68 & 0.60 & 0.55 \\
\hline
\end{tabular}

- : correlation not calculated.

\section{Relation between grain yield and green area duration}

In the quantitative determination of the relation between grain yield and green area duration (D) regression and correlation calculations were applied. The squares of the correlation coefficients indicate which part of the total variance in the grain yield (y) is statistically explained by the concerning $\mathrm{D}$ values $(\mathrm{x})$. These coefficients were calculated between the grain yield and the $\mathrm{D}$ values of the separate green organs during the period from heading and from flowering to ripening. Table 5 shows that the $D$ values during the former period are closer correlated to the grain yield than the $\mathrm{D}$ values during the latter period. The $\mathrm{D}$ values of the flag leaf and the peduncle were very closely correlated with the grain yield in both years. By adding the separate $\mathrm{D}$ values, mainly the combination flag leaf + peduncle gave a higher correlation coefficient in the two years.

No correlation was found between the D values of leaf 3 and the grain yield which suggests that there is no direct contribution of leaf 3 to the ear filling. This is in accordance with the mentioned results of the ${ }^{14} \mathrm{C}$ experiments. The relation between the $\mathrm{D}$ value of the ear and the grain yield differed between the years, which was probably due to differences in the method of determining the green ear area.

The correlations between the grain yield and the green area duration were higher in 'Orca' than in 'Opal', 'Gaby' being intermediate. The regression line of 'Orca' had a somewhat steeper trend than that of 'Opal', which was due to the differing response of the varieties to the sowing date. In 'Orca' the grain yield was more than proportionally lower than the D value, as the sowing date was later, in 'Opal' the grain yield and the D value showed a similar response to late sowing.

The trends resulting form the simple regression and correlation calculations are reflected more distinctly by multiple regression calculations. In the 1967 trial the greater part of the variance in grain yield could be determined by the linear equations:

$\mathrm{Y}=17.3 \mathrm{D}$ flag leaf $+25.0 \mathrm{D}$ peduncle $+141.9 \quad \mathrm{R}^{2}=0.83 \quad \mathrm{n}=72$

In the separate varieties: 
Table 6. Correlation matrix $(r \times 100)$ of the $\mathrm{D}$ values $(1967$ trial).

\begin{tabular}{llrrrrr}
\hline & 1 & 2 & 3 & 4 & 5 & 6 \\
1. D flag leaf & 100 & 86 & 0 & 84 & 79 & 43 \\
2. D leaf 2 & & 100 & 27 & 70 & 75 & 50 \\
3. D leaf 3 & & & 100 & 2 & 32 & 79 \\
4. D peduncle & & & & 100 & 85 & 38 \\
5. D internode 2 & & & & & 100 & 64 \\
6. D ear & & & & & & 100 \\
\hline
\end{tabular}

Opal: $\mathrm{Y}=13.3 \mathrm{D}$ flag leaf $+20.5 \mathrm{D}$ peduncle $+194.3 \mathrm{R}^{2}=0.74 \mathrm{n}=36$

Orca: $\mathrm{Y}:=23.9 \mathrm{D}$ flag leaf $+24.8 \mathrm{D}$ peduncle $+102.7 \quad \mathrm{R}^{2}=0.89 \mathrm{n}=36$

$\mathrm{Y}=$ grain yield in $\mathrm{g} \cdot \mathrm{m}^{-2} ; \mathrm{D}=$ green area duration in weeks.

These equations indicate that flag leaf and peduncle are essential in ear filling. The partial regression coefficients, however, are not of absolute significance, because the D values of flag leaf peduncle are not only closely interrelated, but also correlated with the $\mathrm{D}$ values of other plant organs (see Table 6).

The $\mathrm{D}$ values of flag leaf and peduncle represent in the preceding therefore, a photosynthetic system including more than only their own green areas.

\section{Grain-leaf ratio}

The efficiency of the plant organs with respect to ear filling, indicated in the British literature as grain-leaf ratio $(G)$, is calculated as the quotient of grain yield and green area duration (D).

In 1967 the $G$ value referred to the $D$ values of flag leaf + peduncle and in 1968 to the $D$ values of flag leaf + peduncle + ear (see Table 7), because these $D$ values showed the better correlation with grain yield. The average $G$ value in 1968 was $19.8 \mathrm{~g} \cdot \mathrm{m}^{-2}$.week ${ }^{-1}$, and in 1967 , when the $\mathrm{D}$ value of the ear was included in the calculation, 20.1 g.m-2.week ${ }^{-1}$. When the very late sowing date (5 May) is not included,

Table 7. G values (g.m-2, week-1), calculated from the grain yield and the $D$ value at the final harvest.

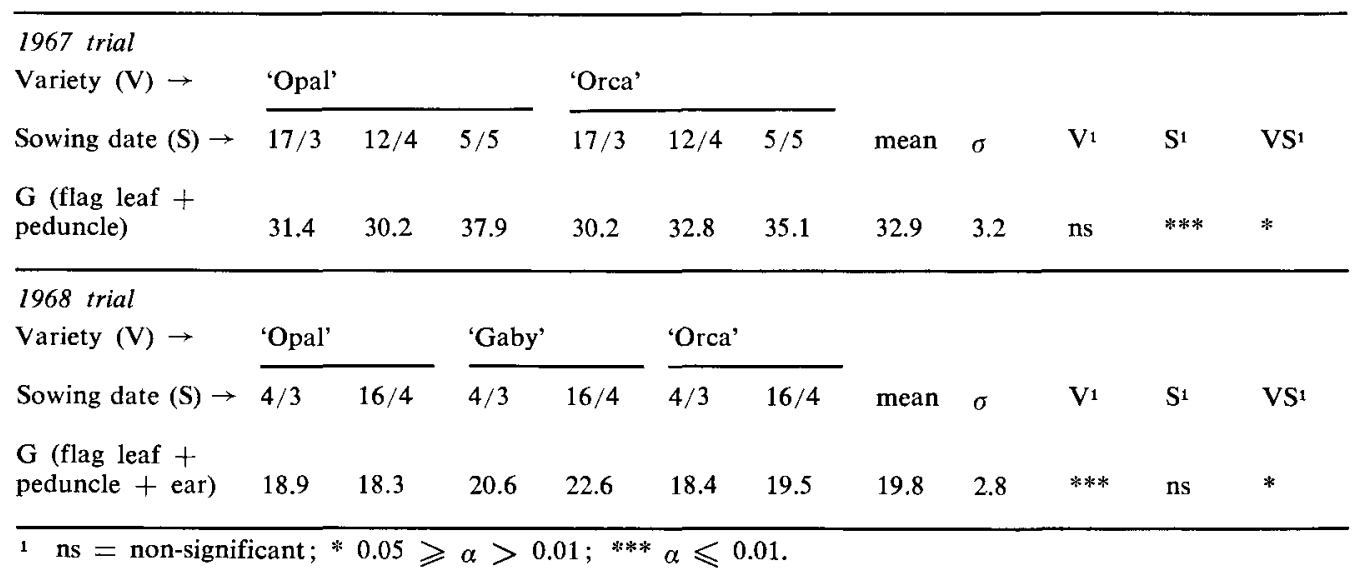


Table 8. The relation between the number of grains and the green area of flag leaf and peduncle.

\begin{tabular}{|c|c|c|c|c|c|c|}
\hline \multirow{2}{*}{$\begin{array}{l}\text { Variety }(\mathrm{V}) \rightarrow \\
\text { Sowing date }(\mathrm{S}) \rightarrow\end{array}$} & \multicolumn{3}{|c|}{ 'Opal' } & \multicolumn{3}{|c|}{ 'Orca' } \\
\hline & $17 / 3$ & $12 / 4$ & $5 / 5$ & $17 / 3$ & $12 / 4$ & $5 / 5$ \\
\hline $\begin{array}{l}\text { Number of grains } \\
\text { per } 10 \mathrm{~cm}^{2} \text { green } \\
\text { area }\end{array}$ & 8.2 & 7.5 & 10.9 & 7.8 & 8.1 & 11.0 \\
\hline
\end{tabular}

the difference in $\mathrm{G}$ value between 1967 and 1968 is greater still: a sunny year and a wet and dark growing season, respectively.

Within the varieties the $G$ value of 'Gaby' was significantly higher than in 'Opal' and 'Orca'. Similar as with the late sowing date, this did not result in a higher grain yield, because the green area duration was proportionally more decreased than the increase in the $G$ value.

The $G$ value was not constant throughout the ear-filling period; in 1968 the $G$ value in the three subsequent fortnight periods after flowering was $26.4,43.0$ and 18.1 g. $\mathrm{m}^{-2}$. week $^{-1}$, respectively. In the first 14 -day period the assimilating area was somewhat larger than in the second, but the rate of ear filling was much retarded, for the period 1 and 2 this was 120 and $170 \mathrm{~kg} \mathrm{ha}^{-1}$.day ${ }^{-1}$, respectively. Immediately after flowering more carbohydrates may have been available than could be utilized by the growing grains. In the third post-floral period the lower $G$ value was probably caused by aging of the assimilating organs.

\section{Discussion}

Various workers state that the grain yield is determined by the quantity of carbohydrates formed by the photosynthetically active green organs for the benefit of the ear filling after flowering. As a measure for the production capacity of carbohydrates the green area duration of special organs is used, viz the flag leaf (lamina and sheath), the peduncle and the ear. Direct ${ }^{14} \mathrm{C}$ analyses of the plant have shown that the greater part of the assimilates produced in the post-floral period in these organs is translocated to the ear. Within this framework two experiments were conducted to study the correlation of the green area duration of special organs of the culm and the grain yield.

The results show (see Table 5) that green area duration calculated of the period from heading to ripening is more closely correlated to the grain yield than the green area duration in the period from flowering to ripening. On the other hand, Welbank et al. (1966) found that the green area duration from flowering to ripening was more closely correlated to the grain yield. However, it is not impossible, though ear filling only starts after flowering, that the photosynthesis in the period between heading and flowering affects the ultimate grain yield. This may be by:

a. re-distribution of the assimilates being temporarily reserved in the peduncle, forming a contribution to ear filling;

b. the effect of the assimilates available before and during flowering on the potential number of fertile grains per ear (Bremner, 1967; Ruckenbauer, 1970) which determine the sink strength of the ear for assimilates. 
The calculations further showed that in 1967 the green area duration of the flag leaf + peduncle gave the better correlation to the grain yield and that in 1968 an essential improvement in the correlation was obtained by also including the $D$ value of the ear in the calculations. The $\mathrm{D}$ values of leaf 2 and internode 2 were less closely correlated to the grain yield, the D value of leaf 3 showing no correlation at all.

Since the D values of the various green parts of the culm were closely interrelated as well (Table 6), it was not possible to calculate the exact contribution of the separate organs in ear filling by regression calculations. The degree of correlation between grain yield and green area duration did indicate which organs were important in ear filling; these were, especially the peduncle (including the sheath of the flag leaf) and the flag leaf, followed by the ear, the last leaf and internode, but one. These also are the organs which to a more or less extent were found to be important as production centres of carbohydrates for ear filling in the literature mentioned in the introduction. The estimated contribution of the separate organs in ear filling was also found to vary with the ${ }^{14} \mathrm{C}$ method depending on the variety, experimental conditions and techniques applied. The older clipping and shading experiments had already shown that in a wheat culm the lost function of an eliminated organ is compensated to a considerable extent by the other green organs. Compensation effects are the greater as the effect of the treatment lasts longer.

For a better understanding of the importance of the crops structure in ear filling the rate of photosynthesis and translocation should be measured in addition to the green area of the organs (Lupton, 1969).

An idea of the average photosynthetic efficiency of the green parts is obtained by the grain-leaf ratio $(G)$. The $G$ value of the late sown treatment in 1967 was strikingly high. One of the reasons for this could be:

a. a higher photosynthetic rate of the relatively young organs accompanied by a higher light intensity in the crop due to the lower density;

b. a greater requirement for assimilates due to the great number of grains per ear.

The effect of the number of grains per ear on the $G$ value can be inferred from the relation between the number of grains and the green area of the flag leaf and peduncle during the first two weeks of the post-floral period.

The parallellism in these figures with the $G$ values (Table 7) shows that the sink strength might influence the $G$ value.

In general it may be assumed that the correlation between green area duration and grain yield will be important, when the green area present cannot yet provide in the carbohydrate requirement of the ear. When sufficient carbohydrates are provided the grain yield is increasingly determined by the sink strength of the ear, i.e. the number of grains.

The efficiency of the green organs, in addition to the internal sink source relation will be influenced by climatical factors, in particular, the light regime in the crop and by the growing conditions, especially the availability of water and nitrogen.

\section{Acknowledgments}

Thanks are due to Mr J. J. van Leeuwen and Mr J. P. J. Geuijen for collecting the data of the 1968 trial, that was a part of their master study and we also thank Mr K. Scholte for technical assistence.

We are very indebted to Miss A. H. van Rossem for translating the manuscript. 


\section{References}

Archbold, H. K., 1942. Physiological studies in plant nutrition. XIII. Experiments with barley on defoliation and shading of the ear in relation to sugar metabolism. Ann. Bot. 6: 487-531.

Asana, R. D. \& V. S. Mani, 1955. Studies in physiological analysis of yield. II. Further observations on varietal differences in photosynthesis in the leaf, stem and ear of wheat. Physiologia Pl. 8: 8-19.

Birecka, H., 1968. Translocation and re-distribution of ${ }^{14} \mathrm{C}$-assimilates in cereal plants deprived of the ear. I. spring-wheat. Bull. Acad. pol. Sci., Sér. Sci. biol. 16: 455-460.

Birecka, H. \& L. Dakic-Wlodkowska, 1963. Photosynthesis, translocation and accumulation of assimilates in cereals during grain development. III. Spring-wheat photosynthesis and the daily accumulation of photosynthates in the grain. Acta Soc. Bot. Pol. 32: 631-650.

Boonstra, A. E. H. R., 1929. Invloed van de verschillende assimilerende delen op de korrelproduktie bij Wilhelminatarwe. Meded. LandbHogesch. Wageningen 33: 3-21.

Bremmer, P. M., 1967. Some aspects of the relationship between growth and yield of wheat. Ph.D. thesis, University of Nottingham.

Carr, D. J. \& I. F. Wardlaw, 1965. The supply of photosynthetic assimilates to the grain from the flag leaf and ear of wheat. Aust. J. biol. Sci. 18: 711-719.

Lupton, F. G. H., 1968. The analysis of grain yield of wheat in terms of photosynthetic ability and efficiency of translocation. Ann. appl. Biol. 61: 109-119.

Lupton, F. G. H., 1969. Estimation of yield in wheat from measurements of photosynthesis and translocation in field. Ann. appl. Biol. 64: 363-374.

Puckridge, D. W., 1968. Photosynthesis of wheat under field conditions. I. The interaction of photosynthetic organs. Aust, J. agric. Res. 19: 711-719.

Rawson, H. M. \& G. Hofstra, 1969. Translocation and remobilization of ${ }^{14} \mathrm{C}$ assimilated at different stages by each leaf of the wheat plant. Aust. J. biol. Sci. 22: 321-331.

Ruckenbauer, P., 1970. Korrelationen zwischen Organmerkmalen von Getreidepflanzen dargestellt an $F_{3}$-individuen einer Winterweizenkreuzung. Bodenkultur $21: 264-280$.

Stoy, V., 1963. The translocation of ${ }^{14} \mathrm{C}$-labelled photosynthetic products from the leaf to the ear in wheat. Physiologia Pl. 16: 851-866.

Stoy, V., 1965. Photosynthesis, respiration and carbohydrate accumulation in spring wheat in relation to yield. Physiologia Pl., Suppl. IV: 1-125.

Thorne, Gillian N., 1965. Physiological aspects of grain yield in cereals. In: 'The growth of cereals and grasses'. Proc. 12th Easter Sch, agric. Sci, Nottingham Univ. (Butterworths, London).

Wardlaw, I. F. \& H. K. Porter, 1967. The re-distribution of stem sugars in wheat during grain development. Aust. J. biol. Sci. 20: 309-318.

Watson, D. J., Gillian N. Thorne \& S. A. W. French, 1963. Analysis of growth and yield of winter and spring-wheats. Ann. Bot. $27: 1-22$.

Welbank, P. J., 1965. Grain yield of wheat and leaf area duration after flowering. Rep. Rothamsted exp. Stn. for 1965: 89-90.

Welbank, P. J., S. A. W. French \& K. J. Witts, 1966. Dependence of yields of wheat varieties on their area durations. Ann. Bot. 30:291-299. 